\title{
Ethical Dilemmas in Management: An African Perspective
}

\author{
Abolaji Joachim Abiodun and Omotayo Joseph Oyeniyi \\ Covenant University, Nigeria
}

\begin{abstract}
The modern workplace is composed of people with diverse backgrounds in terms of nationality, culture, religion, age, education and socioeconomic status. Each of these people enters the work with different values, goals, and perceptions of acceptable behaviours. The diverse background creates ethical challenges for individuals as well as managers. There are issues and decisions that are to be made by workers in the organization that have implications for their job security and salary, and success of the organization. Pressure may be on the workers to protect their own interests, sometimes at the risk of losing personal and corporate integrity. This paper attempts to evaluate ethical dilemmas and conflicts from an Africa perspective, bearing in mind different value systems between western and African nations.
\end{abstract}

\section{Keywords}

Ethics, ethical dilemmas, corruption

\section{Introduction}

There has been increasing demand on business and their managers to behave responsibly and ethically in the conduct of their business activities. This seems understandable since members of society are an input into business process and are in turn affected by the output of business processes. Also, enormous resources are at the disposal of business to prosecute their objectives in a very competitive environment. In positive and negative ways business touches society. Therefore, it becomes reasonable for society to demand that they are socially responsive.

Business is concern with the issue of ethics. This is because businesses are realizing that ethical misconduct by management can be extremely costly not only for the organization but also to society as a whole. For these reasons, global companies and managers need to behave as responsible citizens, that upheld human rights and safeguard the environment, while protecting their own business interests.

Their priorities, it seems are to emphasize "appropriate behaviour" that meet corporate expectations without violating the rights of others (Holt, 1998). The problem, however, in international management is that laws, customs, values and expectations vary across societies. This is so because the practice and approach of business activities vary from one country to another. Thus, maintaining consistent guidelines and ethical codes of satisfactory behaviour in cross-country management in the countries of Africa has been quite challenging.

Ethics is based on broad principles of integrity, transparency, accountability, responsibility and fairness and focuses on internal stakeholder issues such as product quality, customer satisfaction, employee wages and benefits, and local community and environmental responsibilities. These are issues that a company can influence. 


\section{About Nigeria}

There is an evident need in Nigeria: the need to raise the level of standard of living of the populace. For example, in 2004, the Nigerian incidence of poverty was put at $54 \%$ while rural poverty was $63.27 \%$ (National Bureau of Statistics, 2005). This exposed a situation that has sometimes produced intense economic struggle, emulation of the affluence of the western world and unwholesome practice of 'cutting corners'(Olorunfemi, 2008). According to Oshikoya (2008) Nigeria has experienced a prolonged period of economic stagnation, rising poverty levels and decline in ethical values. In 2006, Nigeria was voted as the third most corrupt nation in the world by Transparency International. Nigeria is the world's eighth largest producer of petroleum and has the seventh largest reserves of natural gas. Despite its oil wealth Nigeria is ranked among the twenty-five poorest countries in the world in terms of social indicators (Oshikoya, 2008). This has led to continued concern for ethical issues in the conduct of business activities in the country.

Ethical judgments in Africa and particularly in Nigeria are derived from community values and cultural differences (Gichure, 2006). The high dependency of the economics of African nations on government raises ethical dilemmas that require special attention (Rossouw, 2000). By western standards, ethical lapses occur all over African countries (Gichure, 2000) but particularly in Nigeria. This is so because the level of ethical lapses can be traced to the level of corruption, collapse of moral standards, high level of permissiveness, unemployment and poverty (Oshikoya, 2008).

\section{The Concept of Business Ethics}

Ethics is the discipline dealing with what is good and bad and with moral duty and obligations. Ethics is also defined as a system of moral principles and rules of conduct. Ethical rules of conduct therefore generally attempt to provide guidelines of human behaviours that will preserve a society and its individual mmembers. Put differently, ethics refers to the moral principles that govern the action of an individual or a group. It can mean a set of principles constituting a code of behavior which defines what is good (to be done) or bad and wrong (and thus to be avoided). (Koslowski and Shionoya, 1994).

Business ethics is essentially the study of morality and standards of business conduct (Hodgetls and Luthans 2003). It is simply the application of general ethical rules to business behaviours. Business ethics set standards for conduct perceived to be right and moral by individuals within an enterprise, taking into account the welfare of those affected by business decisions and behaviours (Boatright, 1998). In a major way business ethics concerns itself with the relationship between business goals and practice and the goals of society.

Ethical standards describe expectations to which companies and individuals must conform to remain consistent with widely accepted modes of conduct (Holts, 1998). Business decisions and behaviour may be judged ethical or unethical, depending on whether the decisions and acts promote or threaten the values and standards of individuals and the societies in which a business firm operates.

However, since individuals and societies are constantly evolving and changing their systems of values and beliefs also change. Therefore, ethical standards are not static ideals but dynamic patterns of human conduct, a fact that makes values in a foreign managers' home country, often at odds with the values obtained in the host country. This makes business ethics a complex issue for management across the nations of Africa. Ethical standards, therefore, reflect not a universally accepted code but rather the end product of a process of defining and clarifying the nature and content of human interaction. Unlike noncompliance with a law, a violation of ethical issues does not attract legal sanctions since they appeal more to one's conscience (Charis, 2007).

\section{Efficiency, Competitiveness and Ethics}

Business in its broadest sense involves provisions of services and goods to customers. There is a sense in which every business activity requires a certain level of efficiency and competitiveness. Efficiency refers to the ability, on the part of the entrepreneur or enterprise, to deliver goods and services well to customers, 
without wasting time or resources. This includes, the use of skills, tools, systems, etc. which are needed to produce satisfactory results. Therefore, an efficient firm is one which delivers the highest quality of products and services to its customers, in the shortest possible time, at the lowest possible cost to the enterprise. Competition in business according to Ivancevich, Lorenzi, Skinner and Crosby (1994) is the degree to which a nation or firm can, under free and fair market conditions, produce goods and services that meet the test of international markets, while simultaneously maintaining or expand the real income of its citizens or the firm.

Ethics is as important to the survival of a business as efficiency and competitiveness. Efficiency and competition are business factors. The survival of the society and firms rests on fair and honesty dealings of members of that society to one another. According to Akers (1989) common unethical issues in the western world include back-stabbing through price wars, stealing of corporate plans, and litigation arising from violation of patent rights. Apart from the above, African nations face greater ethical issues that arise out of cultural requirements.

Cultural elements and practices in Africa sometime place African managers in awkward situations: nepotism and employment placement based on ethnic or family ties rather than merit, total disregard for time and appointment in what is referred to as 'African time', leadership cults, complacency, bribery, fraud and paying of 'kickback' (Jaja, 1995).

\section{The Need}

According to Abratt and Penman (2002) the need to study business ethics within the African context becomes imperative because of the following five reasons:

i. Various systems of values and views in the African society about what is right and wrong are reflected in the value systems of individual businessmen and affect business practice. Foreign managers coming from a different value setting may see the need to 'adjust' their behaviour in order to adapt to foreign environments.

ii. Business is a major activity in a society and influence morals both in terms of what it does and through the products it produces.

iii. There are a number of ethical systems in the African society bearing different injunctions to the businessman. As a result, doubts often arise in the mind of the businessman about what is and what is not ethical. As a matter of fact, ethical behaviour in one country sometimes is viewed as unethical behaviour in other countries.

iv. It is difficult to understand business or business-society relationships without knowledge of the ethics and ethical problems of businessmen and what society thinks is the state of business ethics compared with what society expects from business.

v. The benefits derivable from ethics by customers, employees, organizations and the industry demand the study of ethics. Customers on the strength of company's ethical codes can expect that business transactions will be conducted in a fair and honest manner; consequently, confidence in dealing with the enterprise is established.

For employees, ethical codes for managerial and non-managerial behaviour reduce uncertainties; employees are strengthened by the code in their refusal to engage in unethical practice. Organizations' ethical practices serve as a sales and public relations device. As a matter of fact effective self-regulation may serve to prevent external control and government actions.

\section{Approaches to Ethics}

In his analysis of international business ethics De George (1994) identified three main approaches to ethical issues. These are fundamental ethical approaches for executives:

\section{(a). Utilitarian Approach}


This approach focuses on the consequences of an action. The underlying principle is that actions should produce the greater goal for the greatest number of people. Managers who adopt the utilitarian approach judge the effect of a particular action in terms of what provides the greatest good for the greater number of people. This approach in essence, focuses on action rather than on motives behind the action.

Operationally, this approach weighs potentially positive results against potentially negative results. If the former outweighs the latter the manager under this approach will most likely proceed with the action. That some people might be adversely affected by the action is accepted as inevitable.

\section{(b). Moral Right Approach/Deontology}

This approach focuses on the examination of the moral standing of actions independent of their consequences. The question is whether the action is right or immoral, not whether it is beneficial. Thus, managers who subscribe to this approach judge whether decisions and actions are in keeping with the maintenance of fundamental individual and group rights and privileges.

The moral right approach extends/includes the rights of human beings to life and safety, a standard of truthfulness, privacy, freedom of speech and private property.

\section{(c). Social Justice Approach}

This approach judges actions on the strength of how consistent they are with equity, fairness and impartiality in the distribution of rewards and costs among individuals and groups. These ideas stem from two principles: liberty/individual rights principle and the difference principle.

The Liberty/Individual Rights Principle holds that individuals have certain basic liberties and rights compatible with similar rights and liberty by other people. Simply put, one should never take any action that infringes on others' agreed-on rights. Put differently, everyone should act to ensure greater freedom of choice, for this promotes a market exchange which is essential for social productivity.

The difference principle holds that social and economic inequalities must be addressed to achieve a more equitable principle; three implementing principles are essential to the social justice approach: distributive-justice, fairness and natural duty principles.

According to the distributive justice principle, individual should not be treated differently on the basis of arbitrary characteristics such as race, sex, religion or natural origin. On this principle one should act to ensure more equitable distribution of benefits, this promotes individual self-respects, which is essential for social cooperation.

The fairness principle indicates that employees must be expected to engage in cooperative activities according to the rules of the company, assuming that the company's rules are deemed fair (to protect mutual interest of the company themselves and other workers there is a limit to freedom to be absent from work). The natural duty principle is a product of the general obligation of the need to help others who are in need or in danger, the duty not to cause unnecessary suffering and the duty to comply with just rules of an institution.

There are those who base ethical behaviour on the opinions and behaviour of relevant other people (Relativism). They acknowledge the existence of different ethical viewpoints and turns to other people for advice, input and opinions. Group consensus is sought. 


\section{International Management Ethical Dilemmas in Africa}

A universal standard or prescription of rights and wrongs seem difficult to come by when not every culture endorses the same ethical standards. A common phenomenon, however, is the almost universal condemnation of business conduct that violates human rights to live or causes 'excessive' depletion or degradation of the environment. The problem in management across the nations of Africa however, is that human rights or the so-called universal rights are subject to different interpretations. What is valued as right in a country may not be so in another. Thus, few laws apply on an international scale to provide substantial guidelines for corporate conduct (De George, 1994).

Notwithstanding, international management has been concerned with ethical relationships with people who are directly affected by the decisions of foreign companies. This concern ranged from competitive conduct (such as predatory pricing, fraud, bribery, industrial espionage or patent infringements), to environmental protection measures, community relations and financial activities (Holt, 1998). The moral dimensions and consequences (positive and negative) of these issues nevertheless vary across cultures.

These problems are magnified for foreign managers working in Africa in that their foreign assignments, most time, expose conflicts between lifetime of personal moral judgments and standards for decisions in unfamiliar environments. Product safety, for example, may have substantially different meanings in some African countries. Consequently, the personal values of other people and societies often clash with those of expatriate managers.

Furthermore, the roles imposed by foreign assignments may require substantially different expectations than those at home. Often there are contrasts between individual beliefs about ethical behaviour and expectations about behaviour imposed as part of roles or job positions. For example, certain moral obligations inherent in the work roles in foreign assignments often create expectations distinct from people's personal moral beliefs (e.g. Doctors, Lawyers, Engineers, Sales professionals).

Admittedly, domestic managers also encounter role conflict problems but the work roles of a foreign manager in Africa impose far more complex conflicts. This is so because foreign managers need to comply with unfamiliar expectations. The demand of the local environment managers, even in foreign fields, is expected to favour the priorities of stockholders and invests in their decisions. Conflicts, however, arise when other constituent interests arise. For example, decisions by a commercially profitable operation in a foreign field such as oil exploitation in Nigeria's Niger Delta may conflict with the ethical conventions of stockholders in the home country or that of the foreign managers. Managers in consequence may resign or seek to be transferred out of an uncomfortable position. This is so because irrespective of the ethical pressures a company's management and stakeholders expect the manager to perform profitably.

It is on record that international alliances, mergers, and acquisitions can create awkward ethical dilemmas cases of this nature is expressed clearly in situations where foreign subsidiaries, which were as a result of acquisitions, for example, are neck deep in inappropriate business behaviour such as cloning competitors products, bribery, etc. It then became difficult to implement specific sets standards throughout the organization.

Foreign managers, too, become the target of ethical fanaticism where prevailing attitudes recognize one right way of doing business, preempting foreign ideas or laws. Managers from the developed nations encounter difficult relationship in less-developed nations of Africa where conflicting ideologies do not allow stable forms of governance. Foreign managers' attempts to intervene in local policies, improve managerial conduct or address a host country's social issues are often resisted as they are perceived as attempts to impose foreign standards. 


\section{Selected Ethical Issues in Africa}

Ludlum and Pichop's (2008) analysis of business ethics identified certain ethical issues that are prevalent in Africa. These issues include:

\section{(a). Corruption And Bribery}

The practice of paying money or providing benefits to someone in business or government to obtain an inappropriate market, workplace or economic advantage is widely condemned as an unethical practice. This is due mainly to the evil effects of corruption, bribery and fraud. In the true sense these vices convey secret advantages to some competitors on projects, proposals, and bids. This practice is wide spread in most African nations. It is so institutionalized in a number of Africa nations as the only effective way of doing business. In too many cases, bribery in African nations transcends the level of being referred to as unethical to being a common practice (Unruh and Arreola, 2009).

Therefore it reduces innovation and creativity advantages in that it takes business away from a meritbased system. Corruption, bribery, and fraud stymie the economic development resulting from free market competiton. Evidence seems to suggest that these vices especially in the developing nations of Africa hamper the creation of an acceptable legal system, encourage red tape and bureaucracy (Urnruh and Arreola, 2009). They also erode public confidence and trust, and block the development of the infrastructure on which organizations depend.

In view of the destructive influences of corruption, bribery and fraud, companies and individuals are increasingly under demand to adhere to international and national laws governing corruption, bribery and fraud. To eliminate corruption, the Nigerian government established the Independent Corrupt Practices Commission (ICPC) and Economics and Financial Crime Commission (EFCC) while International development agencies such as the World Bank and the International Monetary Fund (IMF) have linked aid disbursement to improvements in administrative practices. Monitoring groups such as Transparency International, through its rankings, draw negative attention to corrupt nations. Overseas banks used by recipients of bribes are been forced to disclose such accounts and freeze them on court orders.

\section{(b). Piracy and Counterfeiting}

Counterfeiting refers to the un-authorized production and sale of exact copies of genuine goods, down to the trademarks. Piracy is mostly used in relation to intellectual property (patents, copyrights and trademarks) and refers to illegal duplication of books, computer programmes, and videotapes. These unethical practices are more prevalent in some countries and are greatly abhorred in some others. This is attributable to the degree of willingness or otherwise of countries to enforce the international copyright pacts that ban illegal duplication and sales of intellectual property.

Piracy and counterfeiting affects society. The firm whose products are being duplicated without receiving royalty or licenses payments losses revenue. Also, there is a high possibility to purchase and use defective components in the production process and final products of genuine products. Fake parts are made of inferior materials and have a shorter life than the genuine article and the usage can be injurious. 


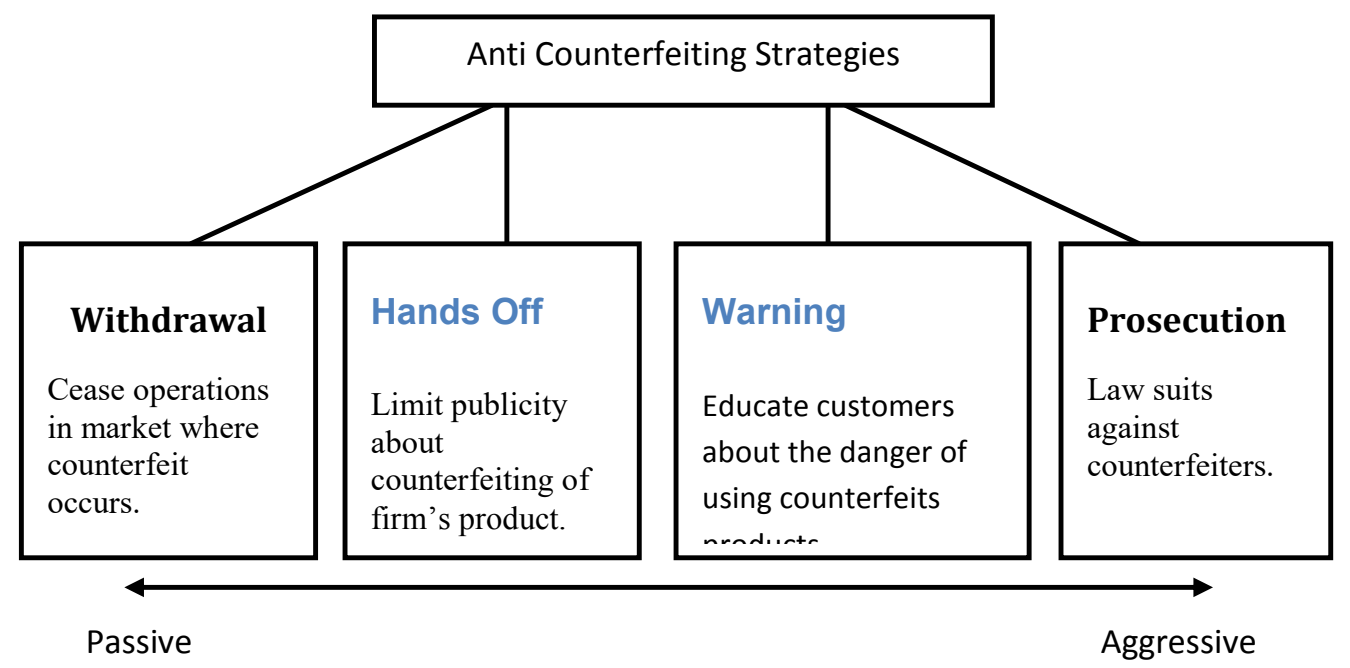

Figure 1. Anti-Counterfeiting Strategies. Source: Sanyal (2001)

Sanyal (2000) identifies four sets of anti -counterfeiting strategies are available to companies.

Withdrawal Strategy: In the withdrawal strategy, the firm exercises greater control over or limit the distribution of their products in the market where the practice is rampant. The withdrawal strategy defends the firm's products and pushes the market consequently; law enforcement agencies may be spurred to take action, especially for strategic goods, e.g. pharmaceutical products. However, in the events of government inaction, counterfeiters may become more established.

Warning Strategy requires that the firm alert consumers about counterfeits of its products. Advertisement and seminars may be undertaken to educate consumers in the features and distinguishing marks of fake and genuine products. The focus is to de-market the fake products by emphasizing the legal and dire consequences of buying counterfeits (components failure, safety risks, and negation of warranty).

Prosecution Strategy: This is an aggressive stand against counterfeiting. The firm focuses on pursuing criminal litigation against the counterfeiters' demands and lobbying government officials and legislators to investigate and prosecute unscrupulous firms and dealers of fake products.

Hand - off Strategy: A company pursues a low-key campaign to curb counterfeiting. The company is unwilling to let consumers know that illegal duplicates of its products are in the market; the fear is that a consumer may switch to the competitors whose authenticity may be less suspect.

\section{(c) Economic Espionage}

This is the obtaining of trade secrets and strategic plans of a competitor by spying; the objective is to obtain vital economic information (Sanyal, 2001). A more mobile workforce and development in information technology that allows vast amount of information to be compressed into small packages and smuggled out of offices and across boarders have aided economic espionage. 
It is not uncommon for government intellectual and security agencies to direct their resources to obtain economic information about other works and companies on behalf of domestic firms and industries. The purpose is to secure advantage for their countries and enterprises in competition. Spies look for vital information in R\&D strategies, new product and processes of manufacturing and marketing plans and customer lists. A host of methods are being used: wire tap or planting of individuals as employees in a competing foreign firm without revealing their true allegiance; theft (vital equipment theft) or bribing of employees; "netspionage" or computer-based espionage has emerged a new security risk for companies. Talented computer hackers can copy data stored in digital format without leaving a trace that they broke into a computer.

A variation of computer-based espionage is using Competitive Intelligence to mine public sources of information and then using appropriate analytical techniques to tie information together creatively. However, firms sometimes resort to industrial espionage to obtain competitive intelligence.

The sum total is the need for multinational corporations to strike a delicate balance between local perceptions of the right things to do and expectations promoted under a parent company's law. The international codes of conduct for corporations can serve as a useful guide in approaching ethical issues in the international arena.

There are a number of obstacles in Africa that frustrate the quest for good corporate governance. Prominent on the list of obstacles are the lack of effective regulatory and institutional frameworks that can ensure the enforcement of the standards of good corporate governance. Lack of transparency and market discipline in those countries without a sound regulatory environment also deter privately owned companies from evolving internally and universally acceptable ethical practices.

\section{(c). Immorality, Force Labour, Discrimination in Employment}

Across the globe the issue of sexual harassment in the workplace is a concern. Further, women managers confront a "glass ceiling" in their attempts to reach top management ranks in some countries. This is not a product of women deficiencies but mainly because of cultural stereotypes, restricted opportunities and discrimination.

Employing prisoners to produce output and restricting employees from leaving a job are ethical problems common to most developing countries.

\section{(d). Price Fixing or 'Cartels' [Competitive Conduct]}

Division of markets among competitors and collusion to fix prices are considered as attempts to unlawfully hurt consumers. Keeping competitors out of the market by excessive control of the marketing channels is also considered unethical.

\section{Conclusion}

A reflection on ethical dilemmas shows inherent conflicts in their resolution. The conflict is more pronounced for managers working in other countries under different cultural orientations. However, ethical dilemma can be resolved through discussion, analysis and collective decision making processes that define the lines of boundaries for foreign managers, taking into consideration organizations' and their managers' personal value systems. This is so because ethical dilemma resolutions may be between two or more personally held values and values held by another person or organization, basic principles and the need to achieve a desired outcome and between two or more individuals or groups to whom one has an obligation (Kirrane, 2009). Resolving ethical issues require the inputs of all stakeholders: multidisciplinary and dimensional approach.

Resolving ethical dilemma, therefore, requires interpersonal and negotiation skills as well as a new application of employability skills: honesty, ability to work cooperatively, respect for others, pride in one's work, willingness to learn, dependability, responsibility for one's actions, integrity and loyalty (Lankard, 2008). Businesses are training their employees in critical analysis and conflict resolution skills required for ethical decision making. More importantly, new employees are sought with these skills and school curricula have also 
stressed the importance these skills to management. The best way to resolve ethical dilemmas is through development of ethical programmes at all levels of an organization.

\section{References}

Akers, J. (1989), 'Ethics and Competitiveness-Putting First Thing First' Sloan Management Review, Winter, pp: 60-71

Boatright, J. R. (1988) "Ethics and the Role of the Manager" Journal of Business Ethics, Vol.7 pp 303-312

Charis, T. (2007), "Rethinking Ethical Issues in Africa Media", African Identities, 5 (1), pp: 39-60.

Hodgelts, R. M. and Luthans, F (2003) International Management: Culture, Strategy and Behaviour New York: McGraw Hill Company Inc.

Holts, D. H. (1998) International Management: Test and Cases, Fortworth: Harcourt Brace and Company

De George; R. T. (1994). International Business Ethics, Business Ethics Quarterly, Vol. 4. No. 1. pp. 1 -9.

Gichure, C. (2000), Fraud and The African Renaissance, Business Ethics: An European Review, 9 (2), 236-247

Gichure, C. (2006), 'Teaching Business Ethics in Africa: What Ethics Orientation? The Case of East and Central Africa, Journal of Business Ethics, 63, pp: 39-52

Ivancevich, J. M., Lorenzi, S. J., Skinner, P. and Crosby, P. (19940, Management: Quality and Competitiveness, NY: Ricard D Irwin

Jaja, S. A. (1995), 'Organized Invisible Spirit' of Management: An Environmental Factor Influencing the Performance of Strategic Organisation in Nigeria', Enugu (Nigeria): Police Administration, Working Paper

Kirrane, D. E. (2009), 'Managing Values: A Systematic Approach to Business Ethics', Training and Development Journal, 54 (11): 53-60

Koslowski, A. and Shinoya (1994), 'The Good and the Economical: Ethical Choices in Economics and Management', Hamburg: Springer- Verlag

Ludlum, M. and Pichop, G. (2008), 'A Preliminary Investigation of Business Ethics in Tanzania', Proceeding of Academy of Legal, Ethical and Regulatory Issues, $12(2), \mathrm{pp} 7-15$

Olorunfemi, S. (2008), 'Public Investment and Economic Growth in Nigeria: An Autoregressive Model', Journal of International Finance and Economics, 5 (3)

Oshikoya, T. W (2008), 'Nigeria in the Global Economy: Nigeria's Integration into the Global Econmy is Below Its Potential,' Business Economics, January, http://www.accessmylibrary.com (accessed 12/3/2010)

Rossouw, G. J. (2005). "Business Ethics and Corporate Governance in Africa". Business and Society, Vol. 44. No. 1. pp. $94-106$.

Sanyal, R. N. (2001) International Management: A Strategic Perspective, New Jersey: Prentice- Hall Inc

Schwartz, M. S. and Weber, J. (2006). “A Business Ethics National Index: Measuring Business Ethics Activities around the World." Business and Society, Vol. 45. No. 3. pp. $382-405$.

Schwartz, M. S. (2001). "The Nature of the Relationship Between Corporate Code of Ethics and Behaviour", Journal of Business Ethics, Vol. 32. pp. 247 - 262.

Unruh, G. and Arreola, F. (2009), 'Global Compliance: Nigeria, http://ethispher.com/global-compliance-nigeria (accessed on 12/3/2010) 
